\title{
On the restricted form of energy-growth nexus: a global level VECM approach and the historical structural breaks.
}

\author{
Luís Miguel Marques ${ }^{1}$, José Alberto Fuinhas ${ }^{2}$, António Cardoso Marques ${ }^{1}$ \\ ${ }^{1}$ Department of Management and Economics, University of Beira Interior, Covilhã, \\ Portugal \\ ${ }^{2}$ Faculty of Economics, University of Coimbra, Coimbra, Portugal
}

Purpose - This paper focuses on global energy consumption using the economic growth nexus, the prevalent energy hypothesis at a global level, and the impact of the main historical events assessed for the period from 1965 to 2015.

Design/methodology/approach - Given the confirmed presence of endogeneity and cointegration between energy consumption and economic growth, a Vector Error Correction with structural dummies model was used. Furthermore, the impulseresponse functions and variance decomposition were computed to evaluate the variables' dynamics.

Findings - Bi-directional causality running from energy consumption to economic growth was found, both in the short and long-run, supporting the feedback hypothesis. It is proved that the 2008 crisis impacted the global energy-growth nexus. Furthermore, there is evidence of the impact of the 1990s oil price shock on the nexus. Innovations in energy consumption have a positive impact on economic growth; however, this impact tends to be null in the long run.

Practical implications - The results suggest that at a global level, any energy policy should be carefully designed in order not to hamper economic growth. Countries should not remain indifferent to the policies that other countries might follow. Very few historical crises impacted on the global energy-growth nexus.

Originality/value - This paper offers a different approach to the study of the energygrowth nexus. The energy-growth nexus is analysed in the major macroeconomic 
aggregate. Global variables reveal their relevance as a benchmark in the energy-growth nexus. Furthermore, this paper arrives at some conclusions about how historical crises impact on global relationships.

\section{Keywords}

Global energy-growth nexus; Vector error correction model; Granger causality.

\section{Acknowledgment}

The financial support of the NECE - Research Unit in Business and Economics, project UIDB/04630/2020 and the CeBER - Centre for Business and Economics Research, project UIDB/05037/2020 sponsored by FCT - Portuguese Foundation for the Development of Science and Technology, Ministry of Science, Technology and Higher Education is acknowledged. The authors thank the anonymous reviewer for their useful comments and suggestions.

\section{Introduction}

Energy markets are becoming widely integrated, and the need for economic growth is a global concern. Projections show that primary energy consumption is projected to increase by 34\% between 2014 and 2035 (BP, 2016) and energy consumption to move from OECD to non-OECD countries, namely China and India. Consequently, global energy consumption is expected to continue to change, over the next few decades, driven by emerging economies. Global primary energy consumption grew rapidly in 2018, with an increase of $2.9 \%$; that is the fastest growth of global primary energy consumption since 2010 (BP, 2019).

Nowadays, achieving universal access to energy, enabling a productive economy, and improving energy efficiency are some of the leading global goals. Accordingly, in $2018, \$ 1850$ billion was invested in providing energy all over the globe and $\$ 240$ billion to improve energy efficiency (IEA, 2019). Global energy investment is expected to continue increasing (see Fig. 1). In short, the energy markets: (i) are experiencing huge changes; (ii) require a high investment level; and (iii) are increasingly global. Further evidence of globalisation is given by the similar movements of Crude and Brent prices, 
as shown in Fig. 1. Additionally, to deal with globalisation, international cooperation on energy policies has been growing over the last few years, for instance, the Europe 2020 strategy, and the 2030 Agenda for Sustainable Development, among others. This cooperation has led to a general acceptance of some principles such as universal access to energy and energy efficiency improvement leading to increasing investment, as stated above.

[Figure 1]

Within this multifaceted situation, understanding the global energy-growth nexus could be problematic. The energy consumption - economic growth relationship depends on local specificities, but it is now accepted as a stylised fact that the nexus is heterogeneous across the globe. Nevertheless, the net effect of the nexus is overlooked in the literature. The use of restricted models provides new information about the global nexus. Indeed, the energy growth nexus should not be treated only as an independent phenomenon by each country or group of countries.

Over the next few years, the need to find a balance between the growing demand for oil and the environmental concerns associated with it becomes even more challenging, especially if this search for an equilibrium impacts negatively on global economic growth. The need to combine economic growth with energy consumption provisions and environmental issues in the current conditions led to the central question of this research: Is there a bi-directional causality between energy consumption and economic growth present at a global level? The extensive attention that the nexus has received in recent years has led to the existence of studies that are mainly focused on individual or panels of countries. However, with increasing market globalisation, the study of the global energy-growth nexus must be worthy of greater interest. Given that energy is an economic production factor, a causality relationship running from energy to growth is a priori expected. If this is true, then changes in energy markets will impact on global economic growth and growing energy demands, leading to an endogeneity phenomenon between them.

Consequently, any change in energy consumption or economic growth can have a bearing all over the globe, especially if a bi-directional causality between energy 
consumption and economic growth is present. Given that endogeneity between the variables could occur, and the relationship between the variables is expected to be a long-run phenomenon, the use of a vector error correction (VEC) model is advised. This econometric technique allows us to treat the variables without the need to distinguish endogenous variables from exogenous, cope with the presence of cointegration, and establish the causal relationships between the variables.

This paper aims to innovate in the energy-growth nexus literature by considering the use of global variables in a way that can constitute an advantageous complementary methodology to the traditional analysis approaches of a single country or group of countries. This approach makes it possible to observe the global dynamics of the variables. Furthermore, some historical periods that could impact on the global nexus are scrutinised. The four traditional hypotheses of the energy-growth nexus were tested, and the results support the feedback hypothesis between energy consumption and economic growth at a global level both in short and in the long-run. This fact reinforces the use of the VEC model as the most suitable one. The 2008 financial crisis was proved to have had an impact on the global nexus. These findings suggest that countries should not remain indifferent to the policies that other countries might follow, how they might influence the energy market, especially those who play a dominant role. Likewise, global variables should not be overlooked in energy-growth research, whether in blocs or in individual country studies.

This paper evolves as follows: Section 2 encompasses a brief literature review; Section 3 provides information on the data and methodology; Section 4 presents the results; Section 5 discusses the results, and Section 6 concludes.

\section{Literature Review}

Research on the energy-growth nexus started when Kraft and Kraft (1978) examined causality relationships for the USA. For decades, it has received considerable attention (Akarca and Long, 1980; Fuinhas et al., 2015; Lee and Chang, 2007; Yu and Jin, 1992). In general, nexus studies have focused on individual country studies (Amri, 2017; Baz et al., 2019; Chandio et al., 2019; Shahbaz et al., 2017), and on panels of countries studies (Ahmed, 2017; Alabi et al., 2017; Keho, 2016; Tiba, 2019). Nexus research has 
advanced in order to solve issues that have arisen. However, nexus research using primary energy consumption and economic growth remains timeless.

Research on the nexus has evolved around the examination of Granger causality between energy and growth (and vice versa), leading to four testable relationships: (i) the neutrality hypothesis(e.g. Alper and Oguz, 2016; Fang and Wolski, 2019; Ozcan and Ozturk, 2019; Śmiech and Papież, 2014); (ii) the feedback hypothesis(e.g. Adams et al., 2016; Saidi et al., 2017; Streimikiene and Kasperowicz, 2016; Yıldırım Durmuş, 2019); (iii) the conservation hypothesis(e.g. Ahmed et al., 2015; Alper and Oguz, 2016; Omri and Kahouli, 2014; Rahman and Velayutham, 2020); and (iv) the growth hypothesis(e.g. Ahmed and Azam, 2016; Baz et al., 2019; Ozcan and Ozturk, 2019; Wang et al., 2011). To put it briefly, the neutrality hypothesis supports that there is no causality between energy consumption and economic growth. The opposite relationship, known as the feedback hypothesis, states that there is bi-directional causality between energy consumption and economic growth. The other two identified hypotheses refer to the existence of unidirectional causality. The conservation hypothesis suggests the existence of unidirectional causality running from economic growth to energy consumption. Finally, the growth hypothesis consists of unidirectional causality running from energy consumption to economic growth.

On the whole, energy consumption can be expected to impact on economic growth. Nevertheless, the effects of economic growth on energy consumption cannot be forecast, as little is known about the interactions of the variables. Despite its importance, global nexus literature is scarce or even lacking. The exception is recently Marques et al. (2015), who found bi-directional causality between energy consumption and economic growth.

Over the years, several methodologies have been used in energy-growth nexus research. The use of vector autoregression (VAR) methodology, assuming stationarity (e.g. Alam et al., 2011; Carmona et al., 2017; Lorde et al., 2010), and studies based on non-stationary series using a correction model (e.g. Armeanu et al., 2017; Saad and Taleb, 2018; Saidi et al., 2017) are far from new in the literature and take a relevant weight in energy-growth nexus research. From the several advantages of this approach, two should be highlighted: (i) it distinguishes the short-run effects from the long-run; (ii) dummy variables may be introduced in order to control for specific periods. 
The control for specific periods on the global energy-growth nexus could be of interest. The impact of structural changes on energy-growth relationships has been studied for blocs and individual countries. Nasreen et al. (2019) found evidence of structural breaks impacting on long-run causal relationships between economic growth and energy consumption for 18 Asian countries. Deichmann et al. (2019) found that structural changes are important contributors to energy intensity, with impacts on energy intensity and economic growth relationships for a panel of 137 countries between 1990-2014. Nevertheless, the impact of structural changes on the global nexus is most likely of two types.

On the one hand, some of the historical and critical periods could have a null global impact because, in many cases, we observe wealth transfer between countries. On the other hand, severe wealth destruction could occur, impacting on the global nexus. Recognizing these cases could assist policymakers in designing global policies when faced with identical harsh conditions.

\section{Methodology}

This paper focuses on the global aggregate energy-growth nexus by studying the dynamics between energy consumption and economic growth. Furthermore, it observes the impact of historical events on the nexus by controlling for structural breaks in the models. Some of the possible periods that could have relevance on the nexus are the 1970s oil shocks in 1973 and 1979, and more recently, the 2008 financial crisis and the 2009 European sovereign debt crisis. On the one hand, the occurrence of 1970s oil shocks might have impacted the global nexus because it led to a lack of petroleum and consequently elevated prices in industrial countries all over the world. On the other hand, financial crises affect relationships by leading to a misspecification of the models and an impact on the trend behaviour of both energy consumption and economic growth. In order to analyse the restricted relationships between energy consumption and economic growth, a bivariate approach is used, and then structural dummies are introduced. The use of bivariate models is frequent in the literature (Fuinhas and Marques, 2012; Odhiambo, 2009; Ozturk et al., 2010). To do so, the use of long-time span variables is mandatory. 


\subsection{Data}

This research uses global aggregate annual data between 1965 and 2015. The real global aggregate gross domestic product was retrieved from the World Bank World Development Indicators, and total global aggregate primary energy consumption from the BP Statistical Review of World Energy. The scarcity of data conditioned the choice of data stretches. In order to use comparable data, it was not possible to extend data before 1965. Let the prefix "L" denote the natural logarithm, and "D" denote the first difference. Table 1 shows the definitions and summary statistics.

[Table 1]

Given the expected endogenous behaviours, the use of autoregressive models is advisable. In order to access the desirable methodology, the variables were evaluated by the unit root tests of Augmented Dick Fuller (ADF), Phillips Perron (PP), Kwiatkowski Phillips Schmidt Shin (KPSS) and the Modified Dick-Fuller (MDF) test, which followed Perron (1989).

\subsection{Model}

By following a Vector Autoregressive (VAR) methodology, it is possible to choose the optimal lag length as well as make a first assessment on possible structural breaks by looking into the VAR residuals. The VAR model specification is:

$$
X_{t}=\sum_{i=1}^{k} \Gamma_{i} X_{t-i}+\varepsilon_{t}
$$

where $X_{t}$ is the vector of endogenous variables, $\Gamma$ is the coefficient matrix of endogenous variables. The residuals are denoted by $\varepsilon_{t}, X_{t}=[D L Y, D L E]$ and $D_{t}=\left[\right.$ Constant, $\left.S D_{y}\right]$, where $S D_{y}$ represents the structural dummies that control for the $y$ years on the nexus. After the VAR estimation, the Johansen cointegration test is performed with the chosen lag length and shift dummies to control for structural breaks when needed.

If the presence of cointegration is proven, the vector error correction model (VECM) is preferred. The VECM approach allows the system convergence to long-run equilibrium, and could be specified as follows: 


$$
X_{t}=\sum_{i=1}^{k} \Gamma_{i} X_{t-i}+\prod X_{t-1}+C D_{t}+\varepsilon_{t}
$$

where $X_{t}$ is the vector of endogenous variables; $D_{t}$ is the vector of exogenous variables; $\Gamma$ is the coefficient matrix of endogenous variables, $C$ is the coefficient matrix of exogenous, and $k$ is the optimal lag number. While $\Gamma_{i}$ captures the short-run dynamics of the model, the $\prod$ captures the long-run relationships. The residuals are denoted by $\varepsilon_{t}, X_{t}=[D L Y, D L E]$ and $D_{t}=\left[\right.$ Constant, $\left.S D_{y}\right]$, where $S D_{y}$ represents the structural dummies that control for the $y$ years on the nexus.

Finally, the validity of the models was evaluated through a battery of diagnostic tests, namely the Jarque-Bera normality test, Langrage Multiplier test for autocorrelation, White heteroskedasticity test.

\section{Results}

Following the methodology, as mentioned earlier, firstly the visual inspection of the variables, as well as the unit root tests (see Table 2 ) revealed that the variables are I(1).

[Table 2]

The MDF test corroborates the integration order of the variables. Moreover, the MDF test alerts for the possibility of structural breaks in 1981, 1990 and 2007. To test the need to control for these periods, before the Johansen cointegration test, a VAR model was estimated. By using the Schwarz information criteria, 2 lags were selected.

[Figure 2]

The VAR residuals (see Fig. 2) suggest the presence of a structural break in 2008. Consequently, the Johansen cointegration test (see Table 3) was performed with a shift dummy from 2008 onwards (SD_2008) as an exogenous variable. 
The Johansen cointegration test supports the presence of cointegration. Following the Johansen technique, the normalised long-run cointegration relationships could be estimated. The equations reveal a bi-directional, positive, long-run relationship between energy consumption and economic growth. Given that the variables are on their logarithms, the coefficients can be interpreted as long-run elasticities (see Fig. 3). We observe that the long-run impacts of energy-consumption on economic growth are higher than the impacts of economic growth on energy consumption.

[Figure 3]

Given the existence of cointegration, the next step is the VEC model estimation. The two optimum lag numbers previously selected were used. The SD_2008 variable was introduced as an exogenous variable allowing the behaviour of the model's residuals to be corrected (see Fig. 4).

[Figure 4]

Further, a shift dummy from 1991 onwards (SD_1991) was introduced and revealed statistical significance. The model surpasses all the relevant diagnostic tests (see Table 4) revealing the desired econometric proprieties of normality, no residual serial correlation and no heteroskedasticity.

[Table 4]

The error correction terms are -0.26 and -0.35 for the growth equation and the energy consumption equation, respectively. As expected, highly significant negative error correction terms were observed, which the system converges to a long-run equilibrium after some disturbance. Any disequilibrium is corrected within approximately four years. Some coefficients of VEC lagged variables are not statistically significant. This could mean that, in the short run, the effects 
between the variables are weak. However, this result should be analysed with caution due to potential overfitting in the VECM. In fact, VECM Granger causality tests revealed short-run impacts running from energy consumption to economic growth, as well as from economic growth to energy consumption, at the statistical significance of $5 \%$ (see fig. 5 ).

[Figure 5]

The VECM variance decomposition and impulse response functions are shown in Table 5 and Fig. 6, respectively.

[Table 5]

The variables reveal dynamic behaviour, which is a requirement of endogeneity. Consequently, the variance decomposition reinforces the results. With regard to LY, after 2 years, shocks to LY explain around 99\% of the forecast error variance when LY ordered first by Cholesky. This impact is reduced to almost $76.8 \%$ at the end of the $10^{\text {th }}$ year. When LE is ordered in first by Cholesky's ordering, shocks to LY explain only $37.8 \%$ of the forecast error variance at the end of the first year. At the end of the $10^{\text {th }}$ year, this impact reduces to around $28.1 \%$. Concerning $L E$, we can observe similar responses to the shocks. When LE is ordered first by Cholesky's ordering, after two years, shocks to LE explain around $62.2 \%$ of the forecast error variance. This impact is reduced to almost $12.71 \%$ at the end of the $10^{\text {th }}$ year. When LE is ordered in first by Cholesky's ordering, shocks to LE explain only $11.3 \%$ of the forecast error variance, at the end of the first year. At the end of the $10^{\text {th }}$ year, this impact grows to around $64.3 \%$. While on the one hand, economic growth is a complex variable which includes the impacts of a lot of variables, including energy, on the other hand, energy consumption is a variable affected by fewer factors wherein economic growth impacts are not evident. As a consequence, the real energy-growth dynamics should be somewhere between the results obtained by the two Cholesky's ordering. The differences found do not influence our conclusions.

The impulse response-functions both in LY and LE are shown in Fig. 5. Given that we generate the impulse response-functions from a VEC model, the graph does not 
show the confidence intervals. Indeed, this display of results is recurrent in the literature (e.g. Marques et al., 2014). In general, the response to a one standard deviation shock in LY leads to a short-run positive impact, that tends to a null impact on LY and a permanent negative impact on LE. Additionally, the responses to innovation in energy consumption are also positive in the short-run. However, in the long-run, they tend to be null on economic growth and permanently positive on energy consumption. In short, the results show that the response of economic growth to innovations on both variables are positive and tend to a null effect. In comparison, the responses to energy consumption are persistent throughout the years.

[Figure 6]

Considering the four traditional nexus hypotheses, statistical evidence for the global feedback hypothesis is found, both in short and in the long-run. Moreover, this paper established statistical evidence of the effect of the 2008 financial crisis on the nexus. It is worth noting that, in the period studied, the recent 2008 financial crisis is the only period of crisis that needed to be controlled for all models. Additionally, evidence of the impact of the 1990s energy crisis on the nexus was found.

\section{Discussion}

The analysis of the global energy-growth nexus could be of particular interest to handle the globalisation of energy markets. There is a growing trend towards global policy-making driven by environmental issues such as carbon dioxide emission levels or the implementation of renewable energies. This new outlook leads to new requirements in energy-growth research. The main objective of this paper is to explore global aggregate energy consumption and economic growth behaviours, by highlighting how they interact both in the short and long-run while unveiling the historical periods of crisis that impact on the whole nexus. At the same time, efforts were made to provide new information for future bloc or country nexus analysis and to demonstrate the quality of the global variables as a benchmark for those studies.

The world energy-growth nexus is stable over a long-time period, given that cointegration was found. The feedback hypothesis was verified both in the short and 
long-run. The revealed dynamics prove that the methodology used was suitable. It should be noted that the 2008 crisis impacted on the global nexus. It was necessary to control for the crisis by introducing a shift dummy from 2008 onwards - this is far from unexpected.

The impact of the 2008 crisis was felt through the bankruptcy of financial companies and the fact that it produced instability in financial markets, namely through an impact on the sovereign debt of some countries. Moreover, a collapse in international global trade was experienced during this period, which negatively affected the transportation sector. Consequently, energy consumption decreased. These behaviours not only highlight the impact of a possible abrupt stop in oil supply but also reveal itself as a signal of globalisation power. This effect agrees with the conclusions of Deichmann et al. (2019), who found that structural changes had an impact on energy intensity and economic growth relationships for a panel of 137 countries, something that can be taken as an approximation to the global relationships. Our model copes with this occurrence, and the global nexus was shown to be highly stable. Additionally, the VECM revealed that the 1990 oil price shock also had an impact on the global energygrowth nexus. It should be said that other periods were tested and revealed no need to be controlled in the models.

In the short-run, the variables exhibit an endogenous nature and similar responses to the shocks. With regard to the long-run, and as expected, an increase in energy consumption promotes economic growth as well as the reverse. This effect reveals the presence of endogeneity between the variables. If primary energy consumption increases, as is expected over the next few years, this will most likely lead to global economic growth, which may increase energy consumption once again. This behaviour can induce inefficient energy consumption, namely by non-productive activities. Therefore, policies paying attention to energy efficiency are required. Indeed, any energy consumption reduction should be made through increasing inefficiency. Without this, any attempts to apply global energy policies that lead to sustained global growth could fail. Increasing energy consumption efficiency should be a global goal to prevent wasteful energy consumption caused by economic growth.

The results reveal a low adjustment speed from any disequilibrium to the longrun equilibrium between the variables, with the adjustment occurring at around five 
years. Also, impacts are occurring from innovations on both variables which are persistent over the years. These results make us aware that energy consumption, as well as economic growth, needs constant innovations that positively drive their growth, suggesting that constant technological development can play a decisive role in the nexus. Additionally, the promotion of diversification will help to make economies more responsive to shocks by improving the adjustment speed on energy-growth nexus. Furthermore, from an energy security point of view, diversification should be promoted, namely for countries that play dominant roles in the nexus, such as China and India, countries that will become increasingly import-dependent over the next few decades.

The results are consistent with those found by Marques et al. (2015), who found bi-directional causality between energy consumption and economic growth, both in the short and long run. More recently, Saidi et al. (2017) found bidirectional causality between energy consumption and economic growth in a global panel of 53 countries. The omission of data for some countries in global models seems to influence the results. On the one hand, our results differ from Chen et al. (2016), who recently took an approach to global results by studying a panel of 188 countries. They found that growing energy consumption causes damage to GDP in the long-run. On the other hand, the results of Antonakakis et al. (2017), point to bi-directional causality between total world energy consumption, and economic growth for a panel of 106 countries with different income levels. These are consistent with those from our paper.

Concerning the literature on countries and groups of countries, our findings accommodate and support them. The proven global aggregate bidirectional causality between energy consumption and economic growth is consistent with the mixed results at disaggregated levels, given that each country has particularities that vanish in the perspective of the global nexus. However, they must be aware that the policies they follow could impact on other countries or regions.

The results of this research suggest that increasing integration should be recommended as a path to be followed by energy markets, especially for countries that play a dominant role in them. In this way, blocs can be created to ensure that no country negatively influences the market, together with the implementation of internal reserves management policies. Furthermore, the accommodation of heterogenous results could be consistent with the quality of the global variables as a benchmark. Introducing global 
variables in the nexus equations for blocs and individual countries could represent a new path of research that should be covered in future research.

Taking into consideration the growing integration of energy markets and policies, supported by our global results, there are a lot of potential countries, such as India or China, that could have the capability to promote spillover effects throughout the globe. Accordingly, the study of spillover effects of countries or groups of countries on the global nexus could be substantial, namely for countries such as China and India. They should play a major role in the global nexus research because it is essential to examine the shift of large amounts of energy that we are experiencing.

\section{Conclusion and Policy Implications}

This study contributes to the literature by providing an overview of energygrowth interactions at a global level. The use of the VEC model approach for annual frequency, from 1965 to 2015, was appropriate to achieve the main goal of a global nexus study. The results prove the presence of feedback hypothesis at a global level both in the short- and long-run. Although a regulatory authority does not exist at a global level, these conclusions are important because; (i) there are attempts to achieve the same goals in several countries, for instance, increasing energy efficiency and reducing pollution levels; and (ii) the implementation of policies in large groups of countries, such as the European Union, can cause global impacts through a contagion effect.

The impact of energy consumption on economic growth was expected. However, the reverse was not so easy to explain. The results proved the presence of cointegration, and the global energy-growth nexus was shown to be regular across the entire long-time span analysed. Although this article does not focus on energy efficiency, it should be said that the possibility of induction of inefficient energy consumption, namely by nonproductive activities, over the next few years, should be taken into consideration. Accordingly, this paper makes clear that any constraining energy policy will most probably hamper economic growth. Making use of efficiency gains could be a possibility.

This paper confirms the presence of global structural breaks. The 2008 financial crisis appears to have had a global impact, as this crisis had asymmetric global effects that negatively impacted on energy consumption and economic growth. Nevertheless, the global nexus proved to be stable. It shows that a country is not indifferent to the 
energy policies another country might follow. Taking this into consideration, going along the path of increasing integration is recommended for energy markets.

Finally, this study draws attention to the quality of global variables for future energy-growth nexus research, given that the results achieved are in accordance with economic theory and are able to accommodate the distinct results existing in the nexus literature. This is an unexplored path of investigation. The use of global variables can add some novelty in the nexus research by (i) using them to analyse the impact of global changes in individual countries or blocs and (ii) using them as benchmarks. The use of global variables as benchmarks could provide new information for the policymakers, for instance, developing integrated policies for blocs of countries at the same benchmark level requiring similar policies to assure sustainable development.

\section{References}

Adams, S., Klobodu, E. K. M. and Opoku, E. E. O. (2016), "Energy consumption, political regime and economic growth in sub-Saharan Africa", Energy Policy, Vol. 96 No., pp. 36-44.

Ahmed, K. (2017), "Revisiting the role of financial development for energy-growth-trade nexus in BRICS economies", Energy, Vol. 128 No., pp. 487-495.

Ahmed, M. and Azam, M. (2016), "Causal nexus between energy consumption and economic growth for high, middle and low income countries using frequency domain analysis", Renewable and Sustainable Energy Reviews, Vol. 60 No., pp. 653-678.

Ahmed, M., Riaz, K., Khan, A. M. and Bibi, S. (2015), "Energy consumption-economic growth nexus for Pakistan: Taming the untamed", Renewable and Sustainable Energy Reviews, Vol. 52 No. Supplement C, pp. 890-896.

Akarca, A. and Long, T. (1980) On the relationship between energy and GNP: a reexamination.

Alabi, O., Ackah, I. and Lartey, A. (2017), "Re-visiting the renewable energy-economic growth nexus", International Journal of Energy Sector Management, Vol. 11 No. 3, pp. 387-403.

Alam, M. J., Begum, I. A., Buysse, J., Rahman, S. and Van Huylenbroeck, G. (2011), "Dynamic modeling of causal relationship between energy consumption, $\mathrm{CO} 2$ emissions and economic growth in India", Renewable and Sustainable Energy Reviews, Vol. 15 No. 6, pp. 3243-3251.

Alper, A. and Oguz, O. (2016), "The role of renewable energy consumption in economic growth: Evidence from asymmetric causality", Renewable and Sustainable Energy Reviews, Vol. 60 No., pp. 953-959.

Amri, F. (2017), "The relationship amongst energy consumption (renewable and nonrenewable), and GDP in Algeria", Renewable and Sustainable Energy Reviews, Vol. 76 No., pp. 62-71.

Antonakakis, N., Chatziantoniou, I. and Filis, G. (2017), "Energy consumption, CO2 emissions, and economic growth: An ethical dilemma", Renewable and Sustainable Energy Reviews, Vol. 68 No. Part 1, pp. 808-824. 
Armeanu, Ş. D., Vintilă, G. and Gherghina, C. Ş. (2017), "Does Renewable Energy Drive Sustainable Economic Growth? Multivariate Panel Data Evidence for EU-28 Countries", Energies, Vol. 10 No. 3.

Baz, K., Xu, D., Ampofo, G. M. K., Ali, I., Khan, I., Cheng, J. and Ali, H. (2019), "Energy consumption and economic growth nexus: New evidence from Pakistan using asymmetric analysis", Energy, Vol. 189 No., pp. 116254.

BP (2016) BP Energy Outlook. http://www.bp.com/content/dam/bp/pdf/energyeconomics/energy-outlook-2016/bp-energy-outlook-2016.pdf. [Online]. Available at: http://www.bp.com/content/dam/bp/pdf/energy-economics/energy-outlook-2016/bpenergy-outlook-2016.pdf.

BP (2019) Statistical Review of World Energy. https://www.bp.com/content/dam/bp/businesssites/en/global/corporate/pdfs/energy-economics/statistical-review/bp-stats-review2019-full-report.pdf. [Online]. Available at: https://www.bp.com/content/dam/bp/business-sites/en/global/corporate/pdfs/energyeconomics/statistical-review/bp-stats-review-2019-full-report.pdf.

Carmona, M., Congregado, E., Feria, J. and Iglesias, J. (2017), "The energy-growth nexus reconsidered: Persistence and causality", Renewable and Sustainable Energy Reviews, Vol. 71 No., pp. 342-347.

Chandio, A. A., Jiang, Y. and Rehman, A. (2019), "Energy consumption and agricultural economic growth in Pakistan: is there a nexus?", International Journal of Energy Sector Management, Vol. 13 No. 3, pp. 597-609.

Chen, P.-Y., Chen, S.-T., Hsu, C.-S. and Chen, C.-C. (2016), "Modeling the global relationships among economic growth, energy consumption and $\mathrm{CO} 2$ emissions", Renewable and Sustainable Energy Reviews, Vol. 65 No., pp. 420-431.

Deichmann, U., Reuter, A., Vollmer, S. and Zhang, F. (2019), "The relationship between energy intensity and economic growth: New evidence from a multi-country multi-sectorial dataset", World Development, Vol. 124 No., pp. 104664.

Fang, Z. and Wolski, M. (2019), "Human capital, energy and economic growth in China: evidence from multivariate nonlinear Granger causality tests", Empirical Economics, Vol. No.

Fuinhas, J. A. and Marques, A. C. (2012), "Energy consumption and economic growth nexus in Portugal, Italy, Greece, Spain and Turkey: An ARDL bounds test approach (1965-2009)", Energy Economics, Vol. 34 No. 2, pp. 511-517.

Fuinhas, J. A., Marques, A. C. and Quaresma, T. N. (2015), "Does oil consumption promote economic growth in oil producers?", International Journal of Energy Sector Management, Vol. 9 No. 3, pp. 323-335.

IEA (2019) World Energy Investment 2019. https://webstore.iea.org/world-energy-investment2019. [Online]. Available at: https://webstore.iea.org/world-energy-investment-2019 (Accessed: 20-08-2019).

Keho, Y. (2016), "What drives energy consumption in developing countries? The experience of selected African countries", Energy Policy, Vol. 91 No., pp. 233-246.

Kraft, J. and Kraft, A. (1978), "On the Relationship Between Energy and GNP", The Journal of Energy and Development, Vol. 3 No. 2, pp. 401-403.

Lee, C.-C. and Chang, C.-P. (2007), "The impact of energy consumption on economic growth: Evidence from linear and nonlinear models in Taiwan", Energy, Vol. 32 No. 12, pp. 22822294. 
Lorde, T., Waithe, K. and Francis, B. (2010), "The importance of electrical energy for economic growth in Barbados", Energy Economics, Vol. 32 No. 6, pp. 1411-1420.

Marques, A. C., Fuinhas, J. A. and Menegaki, A. N. (2014), "Interactions between electricity generation sources and economic activity in Greece: A VECM approach", Applied Energy, Vol. 132 No., pp. 34-46.

Marques, L. M., Fuinhas, J. A. and Marques, A. C. (2015), "On the global energy consumption and economic growth nexus: A long time span analysis", International Energy Journal, Vol. 15 No. 4, pp. 143-150.

Nasreen, S., Mbarek, M. B. and Atiq-ur-Rehman, M. (2019), "Long-run causal relationship between economic growth, transport energy consumption and environmental quality in Asian countries: Evidence from heterogeneous panel methods", Energy, Vol. No., pp. 116628.

Odhiambo, N. M. (2009), "Energy consumption and economic growth nexus in Tanzania: An ARDL bounds testing approach", Energy Policy, Vol. 37 No. 2, pp. 617-622.

Omri, A. and Kahouli, B. (2014), "Causal relationships between energy consumption, foreign direct investment and economic growth: Fresh evidence from dynamic simultaneousequations models", Energy Policy, Vol. 67 No., pp. 913-922.

Ozcan, B. and Ozturk, I. (2019), "Renewable energy consumption-economic growth nexus in emerging countries: A bootstrap panel causality test", Renewable and Sustainable Energy Reviews, Vol. 104 No., pp. 30-37.

Ozturk, I., Aslan, A. and Kalyoncu, H. (2010), "Energy consumption and economic growth relationship: Evidence from panel data for low and middle income countries", Energy Policy, Vol. 38 No. 8, pp. 4422-4428.

Perron, P. (1989), "The Great Crash, the Oil Price Shock, and the Unit Root Hypothesis", Econometrica, Vol. 57 No. 6, pp. 1361-1401.

Rahman, M. M. and Velayutham, E. (2020), "Renewable and non-renewable energy consumption-economic growth nexus: New evidence from South Asia", Renewable Energy, Vol. 147 No., pp. 399-408.

Saad, W. and Taleb, A. (2018), "The causal relationship between renewable energy consumption and economic growth: evidence from Europe", Clean Technologies and Environmental Policy, Vol. 20 No. 1, pp. 127-136.

Saidi, K., Rahman, M. M. and Amamri, M. (2017), "The causal nexus between economic growth and energy consumption: New evidence from global panel of 53 countries", Sustainable Cities and Society, Vol. 33 No., pp. 45-56.

Shahbaz, M., Hoang, T. H. V., Mahalik, M. K. and Roubaud, D. (2017), "Energy consumption, financial development and economic growth in India: New evidence from a nonlinear and asymmetric analysis", Energy Economics, Vol. 63 No., pp. 199-212.

Śmiech, S. and Papież, M. (2014), "Energy consumption and economic growth in the light of meeting the targets of energy policy in the EU: The bootstrap panel Granger causality approach", Energy Policy, Vol. 71 No., pp. 118-129.

Streimikiene, D. and Kasperowicz, R. (2016), "Review of economic growth and energy consumption: A panel cointegration analysis for EU countries", Renewable and Sustainable Energy Reviews, Vol. 59 No., pp. 1545-1549.

Tiba, S. (2019), "Revisiting and revising the energy-growth nexus: A non-linear modeling analysis", Energy, Vol. 178 No., pp. 667-675. 
Wang, Y., Wang, Y., Zhou, J., Zhu, X. and Lu, G. (2011), "Energy consumption and economic growth in China: A multivariate causality test", Energy Policy, Vol. 39 No. 7, pp. 4399-4406.

Yıldırım Durmuş, Ç. (2019), "Investigating energy consumption and economic growth for BRICST countries", World Journal of Science, Technology and Sustainable Development, Vol. 16 No. 4, pp. 184-195.

Yu, E. S. H. and Jin, J. C. (1992), "Cointegration tests of energy consumption, income, and employment", Resources and Energy, Vol. 14 No. 3, pp. 259-266.

\section{Tables}

Table 1. Variables definition and summary statistics

\begin{tabular}{|c|c|c|c|}
\hline \multirow[b]{2}{*}{ Variable } & \multirow[b]{2}{*}{ Definition } & \multicolumn{2}{|c|}{$\begin{array}{l}\text { Descriptive } \\
\text { statistics }\end{array}$} \\
\hline & & Obs. & Mean \\
\hline$L Y$ & $\begin{array}{l}\text { Real world gross domestic product (constant } 2010 \\
\text { dollars) }\end{array}$ & 51 & 31.2182 \\
\hline$L E$ & $\begin{array}{l}\text { Total world primary energy consumption (million tonnes } \\
\text { oil equivalent) }\end{array}$ & 51 & 22.7748 \\
\hline$D L Y$ & $\begin{array}{l}\text { Real world gross domestic product (constant } 2010 \\
\text { dollars) - first differences }\end{array}$ & 50 & 0.0328 \\
\hline$D L E$ & $\begin{array}{l}\text { Total world primary energy consumption (million tonnes } \\
\text { oil equivalent) - first differences }\end{array}$ & 50 & 0.0252 \\
\hline
\end{tabular}

Note: Obs. - Observations

Table 2. Integration order tests

\begin{tabular}{|c|c|c|c|c|c|c|c|c|c|c|}
\hline & \multicolumn{3}{|c|}{$\mathrm{ADF}$} & \multicolumn{3}{|c|}{$\mathrm{PP}$} & \multicolumn{2}{|c|}{ KPSS } & \multicolumn{2}{|c|}{ MDF } \\
\hline & (a) & (b) & (c) & (a) & (b) & (c) & (a) & (b) & (d) & Break da \\
\hline $\begin{array}{l}L Y \\
L E \\
D L Y \\
D L E\end{array}$ & $\begin{array}{c}3.3280^{*} \\
-3.4790^{*} \\
-5.2871^{* * * *} \\
-4.4574^{* * * *}\end{array}$ & $\begin{array}{l}-3.4032^{* * *} \\
-3.1743^{* * *} \\
-4.8400^{* * * *} \\
-4.2601^{* * *}\end{array}$ & $\begin{array}{c}15.0852 \\
8.8723 \\
-1.9635^{*} \\
-2.5601^{* *}\end{array}$ & $\begin{array}{l}-4.3658^{* * * * *} \\
-3.8178^{* * *} \\
-5.1031^{* * * *} \\
-4.4574^{* * * * *}\end{array}$ & $\begin{array}{l}-3.1151^{\text {** }} \\
-2.5830 \\
-4.7240^{* * * *} \\
-4.2601^{* * * *}\end{array}$ & $\begin{array}{c}11.7393 \\
6.0813 \\
-1.7156^{*} \\
-2.5601^{* *}\end{array}$ & $\begin{array}{l}0.1815^{\text {*** }} \\
0.1516^{\text {*** }} \\
0.1166^{\text {* }} \\
0.1636^{\text {** }}\end{array}$ & $\begin{array}{l}0.9588^{* * * * *} \\
0.9179 * * * * \\
0.5368^{* * *} \\
0.3651^{*}\end{array}$ & $\begin{array}{l}-3.5861 \\
-4.2019 \\
-5.7744^{\text {**** }} \\
-5.3738^{\text {**** }}\end{array}$ & $\begin{array}{l}2007 \\
1990 \\
1981 \\
1981\end{array}$ \\
\hline
\end{tabular}

Notes: a) represents the test statistic with trend and constant; b) represents the test statistic with constant; c) represents the test statistic without tendency ar constant; d) for LY represents the test with trend and intercept and break at the trend, for LE represents the test with trend and intercept and break at the trer and intercept, for DLY represents the test with trend and intercept and break at the trend, for DLE represents the test with trend and intercept and break at tl trend. ****, ***, denote statistical significance at $1 \%, 5 \%$ and $10 \%$ levels, respectively

Table 3. Johansen cointegration test

\begin{tabular}{lccc}
\hline Eigenvalue & $\mathrm{H}_{0}: \Gamma$ & Trace & Max-Eiges \\
\hline 0.3772 & 0 & $23.0278^{* * * *}$ & $22.7327^{* * *}$ \\
0.0127 & 1 & 0.0061 & 0.2952
\end{tabular}

Notes: $\mathrm{r}$ indicates the number of cointegrating relationships. *** denotes statistical significance at $1 \%$ level. MacKinnon-Haug-Michelis (1999) p-values. Deterministic trend assumption of test: Intercept (n trend) in cointegration equation and test VAR. Exogenous variables: SD_2008 
Table 4. Diagnostic tests

\begin{tabular}{lccccccc}
\hline Lags & LM-Stat & Component & Skewness & $\chi^{2}$ & Kurtosis & $\chi^{2}$ & Jarque-Ber: \\
\hline Autocorrelation LM test & \multicolumn{2}{c}{ Normality tests } & & & & & \\
1 & 7.2261 & 1 & 0.2027 & 0.3285 & 3.3450 & 0.2380 & 0.5665 \\
2 & 4.3404 & 2 & -0.4839 & 1.8731 & 3.0774 & 0.0120 & 1.8861 \\
3 & 5.4078 & Joint & & 2.2017 & & 0.2500 & 2.4516 \\
4 & 3.7159 & & & & & & \\
White heteroskedasticity & $\chi^{2}$ & & & & & & \\
& 38.3704 & & & & & & \\
\hline
\end{tabular}

Table 5. Variance decomposition

\begin{tabular}{|c|c|c|c|c|c|}
\hline \multirow{2}{*}{$\begin{array}{l}\text { Cholesky ordering: } \\
\text { Year }\end{array}$} & \multirow[b]{2}{*}{$\mathrm{SE}$} & \multicolumn{2}{|c|}{ LY, LE } & \multicolumn{2}{|c|}{ LE, LY } \\
\hline & & LY & LE & LY & LE \\
\hline \multicolumn{6}{|l|}{ Decomposition of $L Y$} \\
\hline 1 & 0.0118 & 100 & 0 & 37.8380 & 62.162 \\
\hline 2 & 0.0165 & 99.0642 & 0.9358 & 32.0179 & 67.982 \\
\hline 5 & 0.0209 & 77.1162 & 22.8838 & 28.7003 & 71.299 \\
\hline 10 & 0.0279 & 76.7877 & 23.2123 & 28.1337 & 71.866 \\
\hline \multicolumn{6}{|l|}{ Decomposition of $L E$} \\
\hline 1 & 0.0134 & 62.1620 & 37.8380 & 0 & 100 \\
\hline 2 & 0.0191 & 37.5354 & 62.4646 & 11.2844 & 88.715 \\
\hline 5 & 0.0265 & 13.4456 & 86.5544 & 50.9687 & 49.031 \\
\hline 10 & 0.0287 & 12.7146 & 87.2854 & 64.2637 & 35.736 \\
\hline
\end{tabular}

\section{Figures}

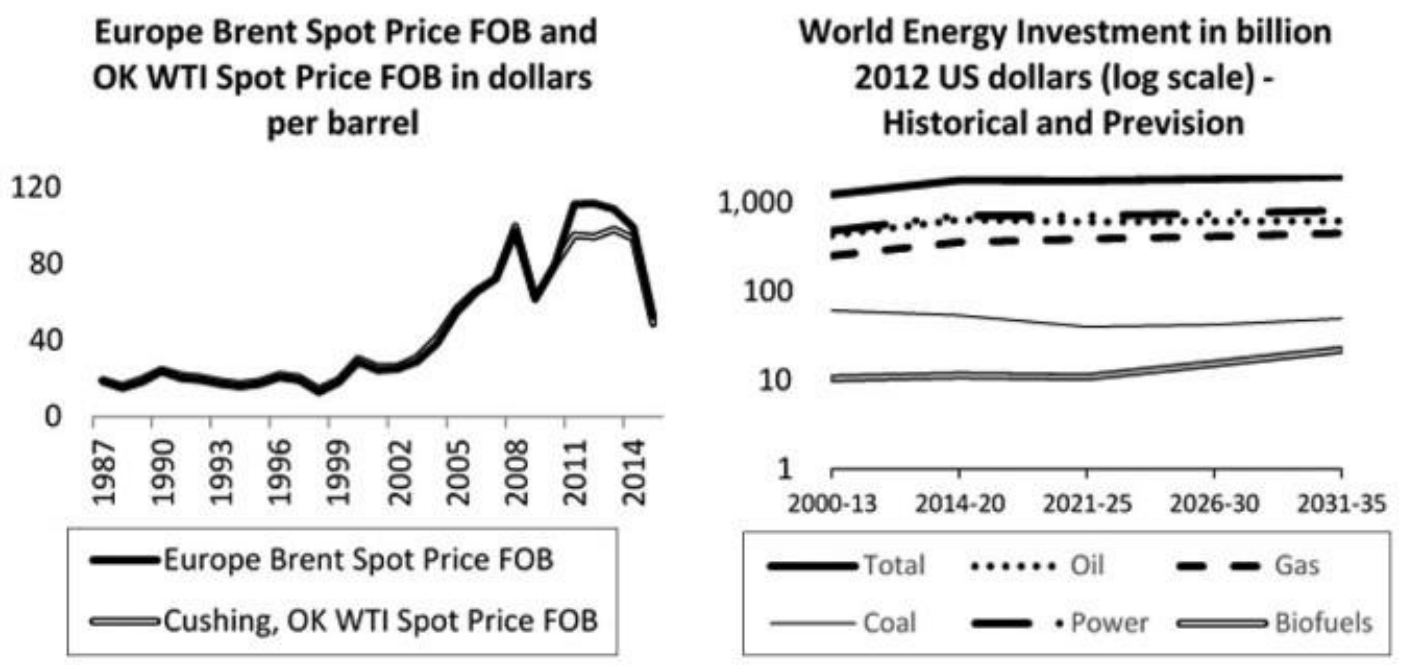

Figure 1. Brent and WTI Spot Prices and World Energy Investment - Historical and Prevision 

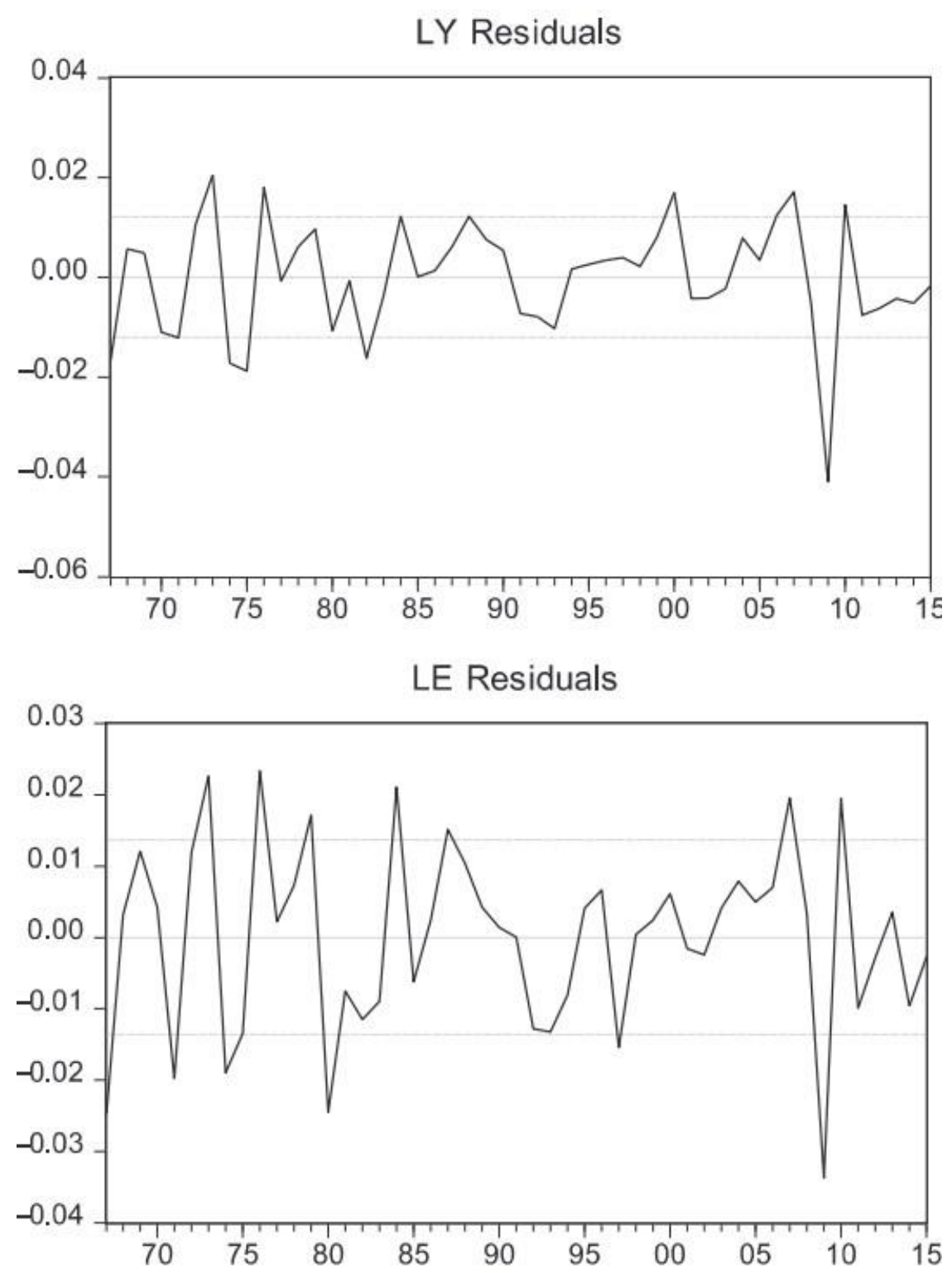

Figure 2. VAR residuals

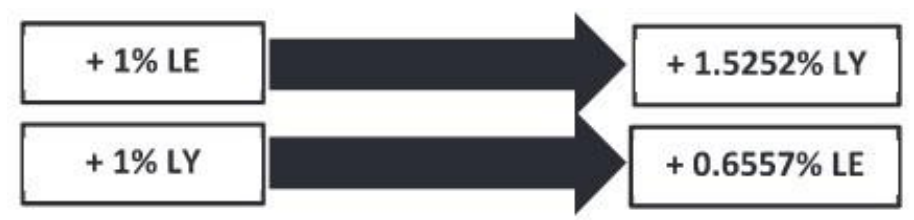

Figure 3. Long-run elasticities 
LYResiduals

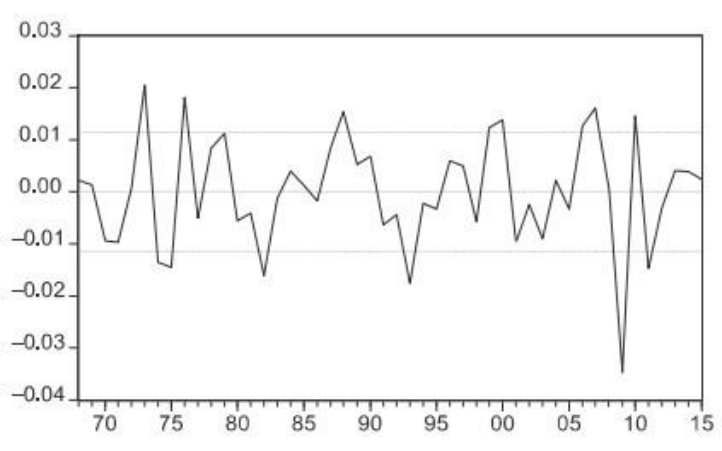

LY Residuals

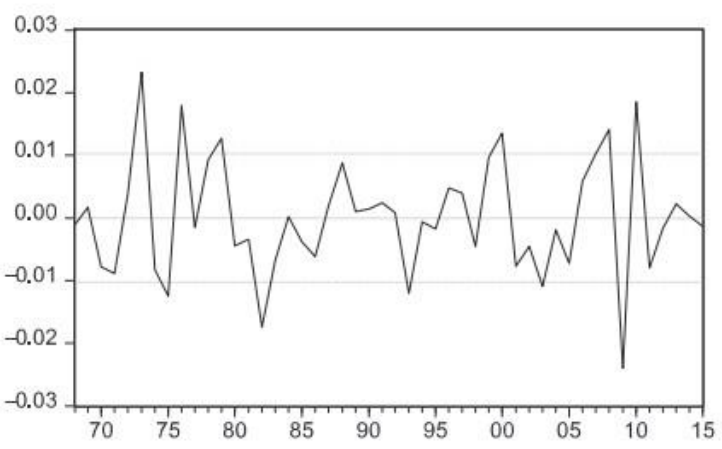

LE Residuals

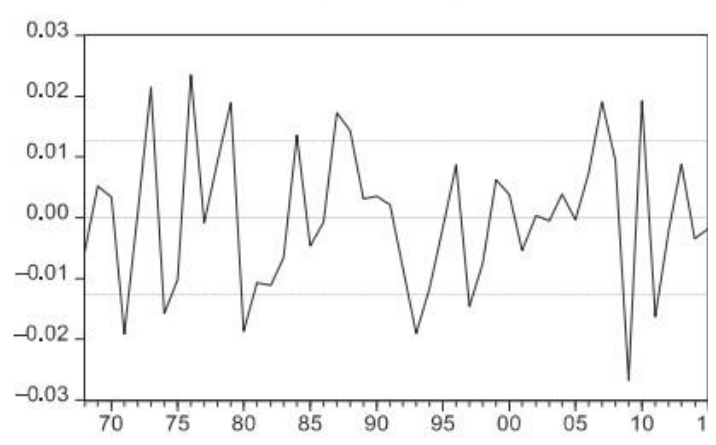

LE Residuals

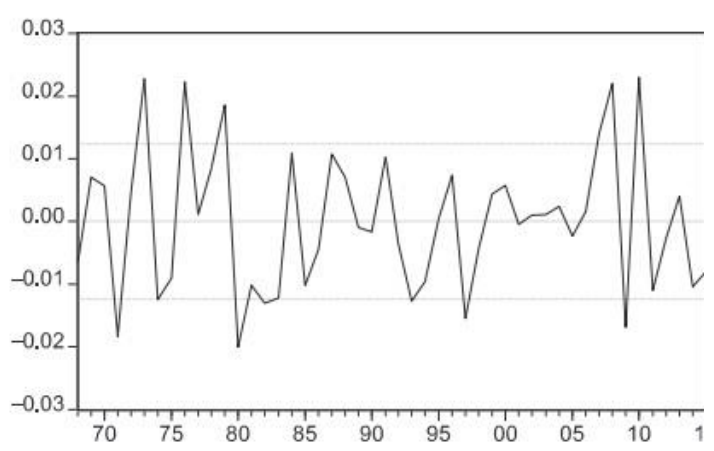

Figure 4. VECM residuals

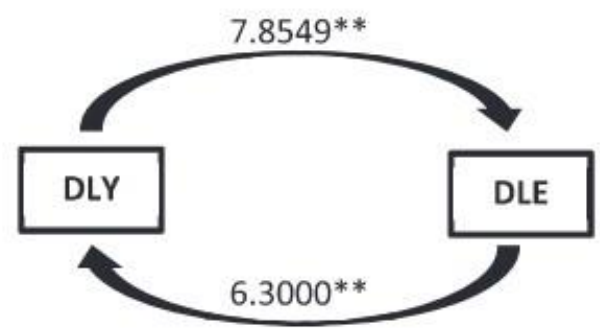

Note: **Denote statistical significance at $5 \%$ level

Figure 5. VECM Granger causality tests 


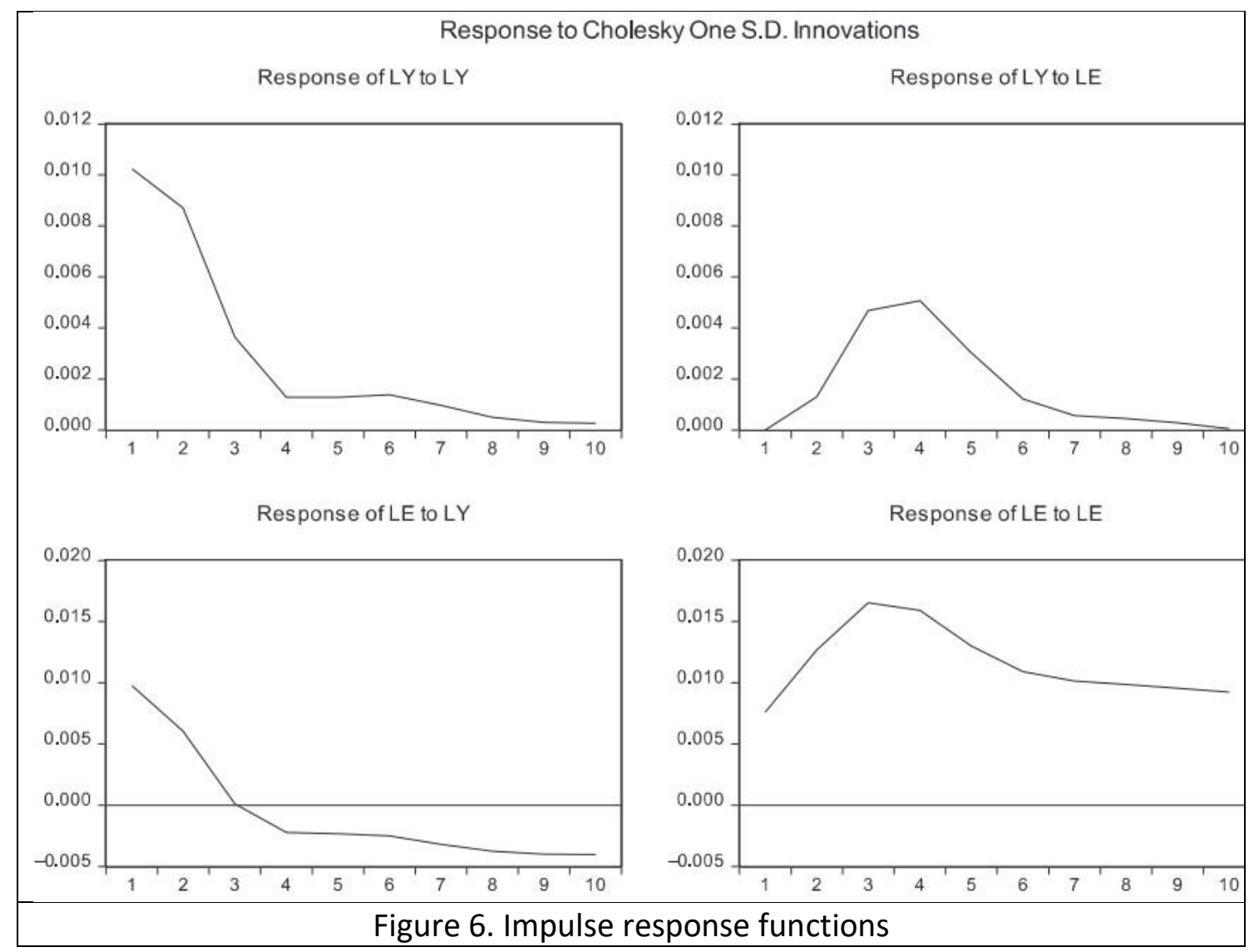

